\title{
Contact and thermal analysis of an alumina - steel dry sliding friction pair considering the surface roughness
}

\author{
Zoltán Lestyán ${ }^{\mathrm{a}, *}$, Károly Váradi ${ }^{\mathrm{a}}$, Albert Albers ${ }^{\mathrm{b}}$ \\ ${ }^{a}$ Institute of Machine Design, Budapest University Technology and Economics, Budapest, Müegyetem rkp. 3., H-1111, Hungary \\ ${ }^{\mathrm{b}}$ Institute of Product Development Karlsruhe, University Karlsruhe, Karlsruhe, Kaiserstraße 10., D-76131, Germany
}

Available online 2 May 2006

\begin{abstract}
In the present study, finite element transient contact and thermal sliding simulation and temperature measurement of dry sliding friction were performed in order to analyse the real contact area and temperature developed in the contact region. Real 3D surface worn topographies were taken into consideration, at macro and intermediate stages. The calculated real contact area has been changing in time and space in the course of sliding. The sliding components were high purity alumina ceramic palettes and 100Cr6 steel with constant accelerated motion. The calculated temperature results are in good agreement with the temperature data measured. Heat partition was changing in time during sliding. The developed algorithm based on incremental FE technique can characterize real processes.

(C) 2006 Elsevier Ltd. All rights reserved.
\end{abstract}

Keywords: Real contact area; Surface temperature; Dry sliding friction

\section{Introduction}

Alumina-steel sliding pairs are used in several kinds of power transmission units. Understanding of contact and thermal processes during their sliding friction leads to the utilization of the advantages of the counterparts for different applications. The advantages of alumina include good heat conduction, high compression strength, high thermal stability, wear resistance and low cost; however, it is brittle. At the same time the steel is ductile with good thermal conduction properties. Nowadays this kind of sliding pairs is able to respond higher requirements against power trains, such as higher transferred power which generates higher temperatures.

The precise measurement of contact temperature is limited, although it can yield surface temperature directly. In this field there are several methods and applications, including: Tian and Kennedy [1] by special thin film thermocouples; Vernersson [2], Arslan et al. [3] by thermo camera; Tkachuk and Bogdanovich [4] by optical-electron scanning technique. Parallel to these research activities, analytical approaches to determine the surface temperature

\footnotetext{
${ }^{*}$ Corresponding author.
}

of a sliding pair were presented in the first half of the 20th century. Blok [5] and Jaeger [6] determined the maximum surface temperature rise for single semi-infinite body by uniform heat source. The definition of heat partition came from Blok; its condition was the identical maximum contact temperatures. Archard [7] simplified the assumption mentioned above and applied it in the cases of slow and fast moving contacts. The refined calculation of temperature in the vicinity of the contact area was provided by Carslaw and Jaeger [8]. Allen [9] solved numerically the general problem of heat partition and later on KuhlmannWilsdorf [10] introduced an approximate solution of heat partition at intermediate velocities in elliptical contact areas. Tian and Kennedy [11-13] analysed the temperature state at macro stage and micro stage analytically. Based on results by Carslaw-Jaeger, Bos and Moes [14] yielded the identical contact temperature in the elliptical contact region by an algorithm developed. Abdel-Aal et al. [15] studied the contact of summits and temperature development considering temperature dependent thermal properties. Váradi et al. [16] modelled the contact area distribution and contact temperature developed in rubbing surfaces by a surface substituting technique and finite element analysis. Muzychka and Yovanovich [17] studied 
the surface temperature development in the case of rectangular and elliptical contacts in all cases of Peclet numbers by an algorithm evolved. Hou and Komanduri [18] investigated the surface temperature developed in the course of a fine grinding process which is a case of sliding friction of rough surfaces. In their calculation they took the heat partition of worn chips into consideration. Most of the calculations did not use temperature dependent material properties while Ling and Rice [19] analysed the effect of temperature dependent thermal properties on thermal processes. Hwang and Zum Gahr [20] were predominantly active in the field of monolithic alumina ceramics and $100 \mathrm{Cr} 6$ steel sliding pairs.

The aim of this work is to study the contact and thermal behaviour of a dry sliding friction system, considering real worn surface topographies. Contrary to the calculations using constant velocity and constant coefficient of friction, this study analyses a real application of dry sliding friction with constant acceleration and time dependent coefficient of friction.

In most of the cases, the macro and micro scale analysis of the thermal processes of sliding friction are used, which are capable to characterize the macro environment or only a small area of the contact. A better way to reach the goals is a three-level analysis, by macro, intermediate and micro scales. The total temperature development of the test rig can be compared by three-level analyses. The first level is the macro scale analysis which provides the global temperature state. The second level analysis is the intermediate scale analysis which determines the thermal state in the contact region considering the surface roughness of rubbing surfaces. The third level is the micro scale sliding simulation which yields the real flash temperatures.

This study analyses the contact and thermal processes on the whole contact region applying macro and intermediate scale analysis assuming two-body friction. The next chapter covers the experiments; the FE contact and thermal sliding simulation will be expounded in the following order: determination of contact area, boundary conditions and load models of the transient thermal analyses and finally the reference measurements.

\section{Friction test and measurements}

The aim of the measurement was to provide data about the physical/mechanical/thermal phenomena during the dry sliding friction process. The test rig could perform a component test; this kind of test is the third level of the tribological test after the model test and the semitribocouple test [21]. The parts of the rig are shown in Fig. 1. Six ceramic palettes on the same pitch circle were fixed in the gripping head and the steel disc was stationary. The assembly of the test rig and the materials of their parts are shown in Fig. 2. The material properties are presented in Table 1.

The measured data-like the coefficient of friction, the applied normal force and the friction torque - of the test

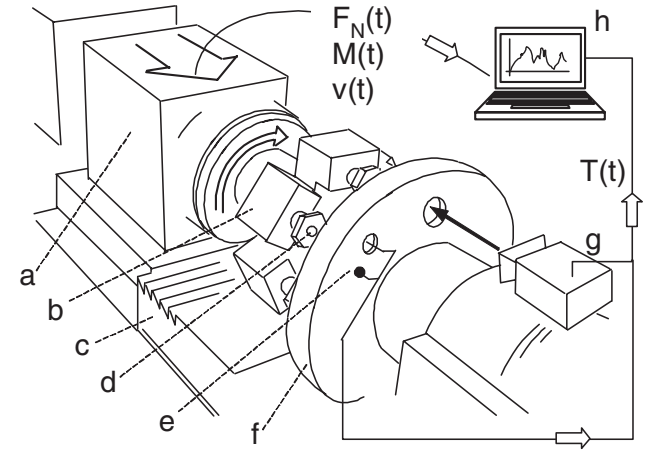

Fig. 1. The assembly of the test rig: (a) the power train, (b) rotating gripping head, (c) feeding unit, (d) ceramic palettes, (e) thermocouples, (f) stationary steel disc, (g) thermo camera and (h) computer.

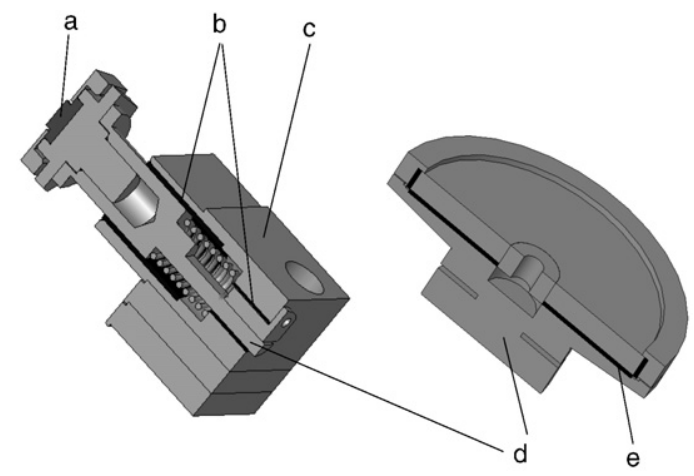

Fig. 2. The built in materials, (a) alumina ceramic, (b) polymer, (c) aluminium, (d) steel, (e) thermal insulator.

Table 1

The built in material properties

\begin{tabular}{llclc}
\hline Material ID & Component & $\lambda(\mathrm{W} / \mathrm{mK})$ & $\rho\left(\mathrm{kg} / \mathrm{m}^{3}\right)$ & $c(\mathrm{~J} / \mathrm{kgK})$ \\
\hline I & Steel & 35 & 7800 & 460 \\
II & $\begin{array}{l}\text { Thermal } \\
\text { insulator }\end{array}$ & 0.37 & 1800 & 800 \\
III & Ceramic & 30 & 3900 & 900 \\
IV & $\mathrm{Al}_{2} \mathrm{O}_{3}$ & 221 & 2700 & 500 \\
V & Aluminium & 221400 \\
\hline
\end{tabular}

constitute the inputs for latter calculations. The total normal force was constant $600 \mathrm{~N}$, which means that the average pressing force $\left(F_{N}\right)$ is $100 \mathrm{~N}$ for each ceramic palette. The friction test was made up of a series of individual steps. An individual step consists of the following parts:

Between 0 and $5 s$ : Normal force was acted between the six ceramic palettes and the steel disc.

The gripping head with the ceramics was rotated against the stationary disc. The variation of rotational speed in time is shown in Fig. 3. 


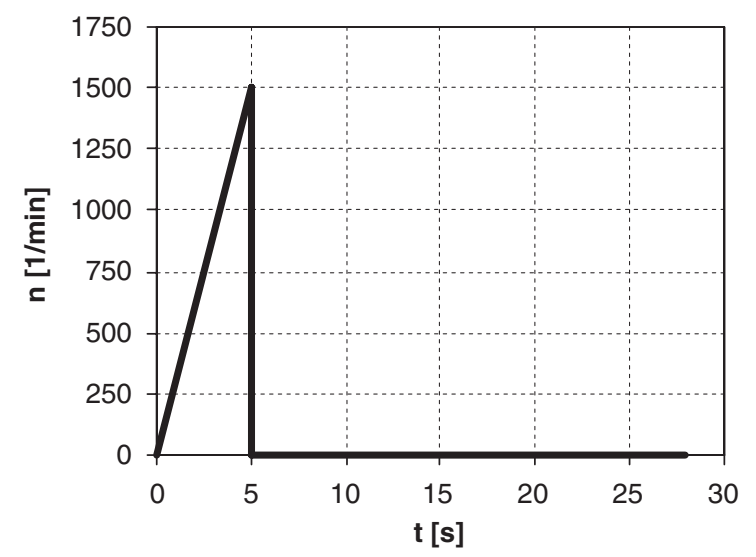

Fig. 3. The speed of rotating gripping heads of an individual step of the friction test in time.

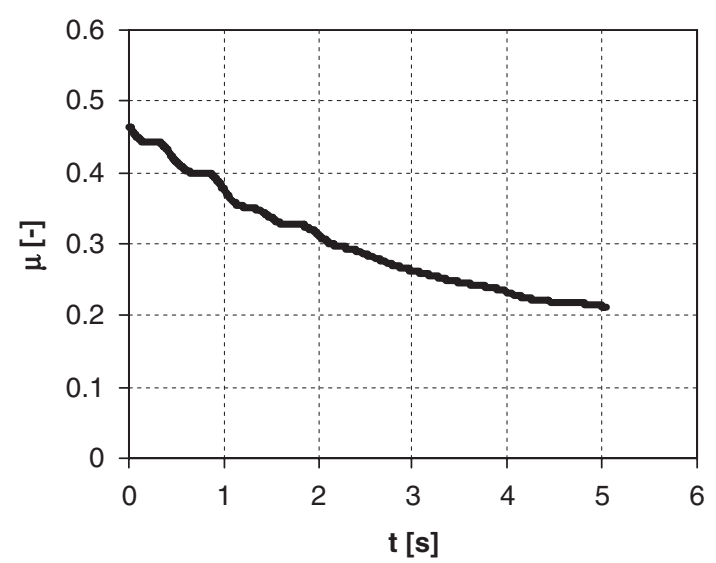

Fig. 4. The average of coefficient of friction of the first ten friction test measured in time.

Between 5 and $28 s$ : The connection was disengaged, the rotation was stopped and the whole system cooled down in the following $23 \mathrm{~s}$.

This step was repeated by 300 times. The room temperature was $27^{\circ} \mathrm{C}$. The variation of the coefficient of friction in time of the first ten steps had the same character, thus their average, which is shown in Fig. 4, could characterize the behaviour of the latter steps.

The present simulations use the worn topographies of the sliding pairs after 300 repetitions. The running in process at the beginning can characterize only a short interval of the whole lifetime; at the same time, if we apply worn topographies in our calculations as initial conditions we can characterize the behaviour of a larger section of the lifetime.

\section{Macro scale thermal analysis}

\subsection{Estimation of the nominal contact area}

Macro analysis provided the global temperature state of the test rig. The thermal calculation was based on the determination of the contact area. Based on 3D surface roughness measurements, the estimated nominal worn area $A_{W}$ of the ceramic palette was assumed as the nominal contact area, which had an ellipsoidal form as it can be seen in Fig. 5. The contact area was assumed to be constant during the sliding. It was assumed that the whole nominal contact area is in contact.

\subsection{Analysis of the steel disc}

\subsubsection{Moving heat source model}

The ceramic rubbing surface is subjected to a stationary heat source while a moving one evolved on the steel disc. We defined the contact area directly from the topography of the worn ceramic palette, without any contact calculation, that was the input of the thermal calculations below. The moving heat source FE model was a local model of the stationary steel disc, as can be seen in Fig. 6. The moving heat source modelling could describe local heat generation during sliding. An incremental technique was applied during the transient contact and thermal sliding simulation. The continuous movement was approximated by incremental steps of $1 \mathrm{~mm}$ sliding distance. The initial condition of the actual step was the temperature distribution of the previous step. The thermal load is the heat generated, which was applied by uniform heat flux power

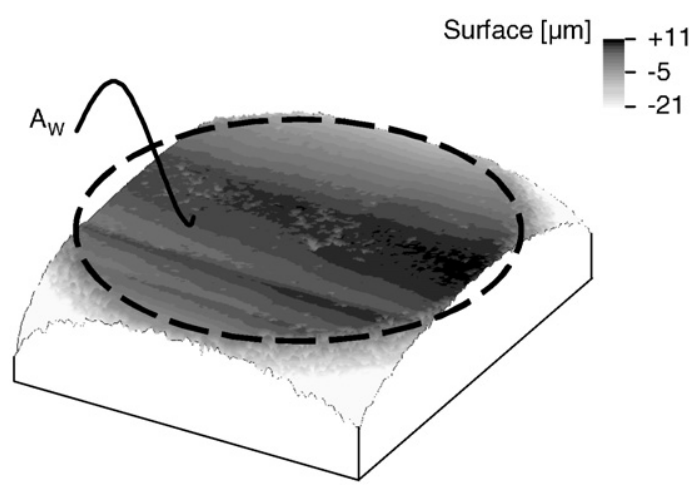

Fig. 5. The estimated nominal worn area, $A_{W}$.

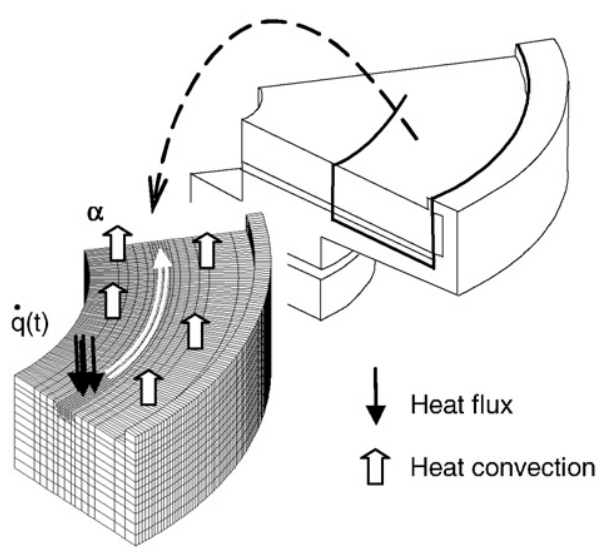

Fig. 6. The moving heat source model of the steel disc. 

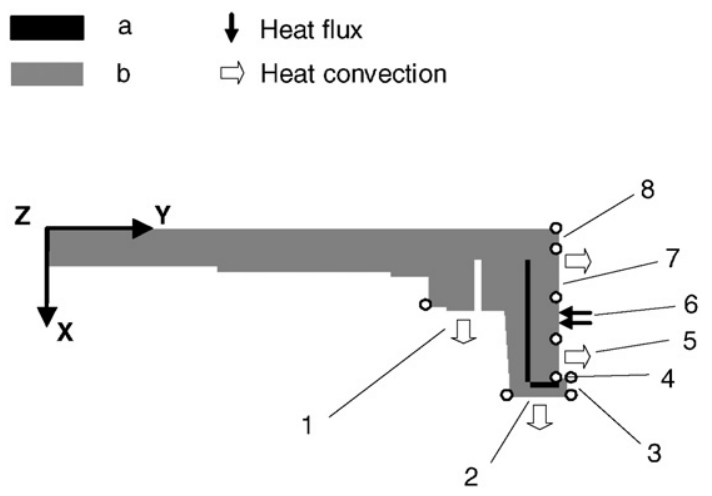

Fig. 7. The axisymmetrical model of steel disc: (a) thermal insulator, (b) steel.

on the nominal contact area; that is

$\dot{q}(t)=\beta(t) p \mu(t) v(t)\left[\mathrm{W} / \mathrm{m}^{2}\right]$

and

$p=F_{N} / A_{W}[\mathrm{~Pa}]$,

where $\beta(t)$ is the heat partition of the steel disc, $p$ is the constant nominal uniform pressure, $\mu(t)$ is the coefficient of friction, $v(t)$ is the velocity, $A_{w}$ is the estimated nominal worn area, and $F_{N}$ is the normal load. The applied surface heat convection model as defined by Section 3.5.

The 3D moving heat source thermal analysis could describe short sliding (e.g. several seconds), while axisymmetric modelling could simulate longer periods due to the stationary heat source and the smaller model size. The axisymmetric modelling of the steel disc used a distributed heat source, so it could not provide the local effects of concentrated heat input, but it can characterize the whole test rig.

\subsubsection{Axisymmetric model}

The axisymmetric model of the steel disc is shown in Fig. 7; the applied load was a distributed heat source

$\dot{q}(t)=\beta(t) p \mu(t) v(t) \quad\left[\mathrm{W} / \mathrm{m}^{2}\right]$,

$p=F_{N} / A_{S}[\mathrm{~Pa}]$

$A_{S}=2 * R * \pi * b\left[\mathrm{~m}^{2}\right]$,

where $A_{S}$ is the ring surface of worn groove, $R$ is the radius of the pitch circle, $b$ is the semi major axis of estimated nominal worn area. The boundary condition was surface heat convection which is defined by Section 3.5.

\subsection{Analysis of a ceramic side}

The axisymmetric FE model of a ceramic and its carrier (ceramic side) is shown in Fig. 8. The applied load was uniform heat flux power on the nominal contact area:

$$
\begin{aligned}
& \dot{q}(t)=(1-\beta(t)) p \mu(t) v(t)\left[\mathrm{W} / \mathrm{m}^{2}\right], \\
& p=F_{N} / A_{W}[\mathrm{~Pa}],
\end{aligned}
$$
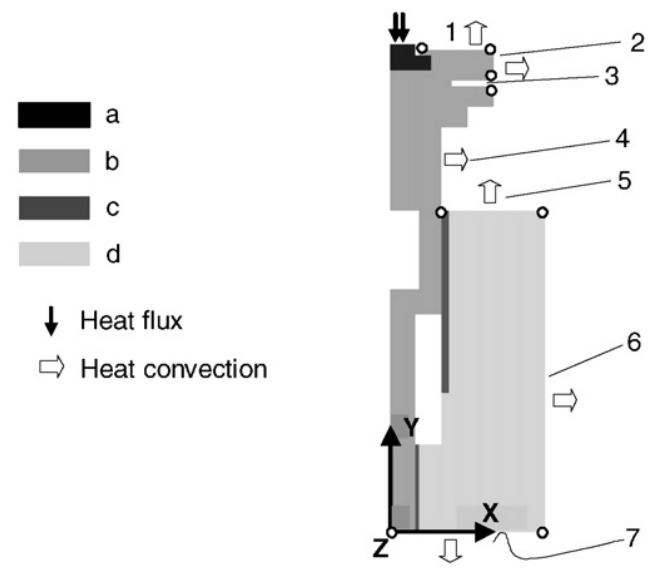

Fig. 8. The axisymmetrical model of ceramic side: (a) ceramic, (b) steel, (c) polymer, (d) aluminium.

the thermal boundary condition was defined according to Section 3.5.

In the FE model of the ceramic side, the solids were cylindrical due to the axisymmetric modelling contrary to the carrier with rectangular solid shape. The effect of the modelled shape and the real shape of the carrier was negligible due to the thermal insulation of the polymer journal bearing. Thus the application of the axisymmetric model in the case of the ceramic side was adequate.

\subsection{Heat partition}

The loading heat flux is proportional to heat partition hence it is an important function in time. As can be read in the introduction, there are several ways to determine heat partition which is the ratio of heat transferred into the counterparts. In this study a special iterative algorithm was applied to determine it based on finite element transient thermal calculation. In this algorithm the axisymmetric FE model of the ceramic side and the moving heat source transient thermal model of the steel disc were used. The maximum temperatures of the two rubbing surfaces were compared in each incremental step of $1 \mathrm{~mm}$ sliding. The algorithm modified heat partition and repeated the transient thermal calculation in the same position until the difference of maximum temperatures were below $1{ }^{\circ} \mathrm{C}$. After the condition came true, the transient analysis progressed by the next $1 \mathrm{~mm}$ step. In the case of slow sliding the heat partition calculated by the heat conduction coefficient was suitable; for this reason the initial condition for steel-ceramic heat partition was always $54-46 \%$, respectively.

\subsection{Evaluating of surface heat convection by the flow model}

The main thermal boundary condition of transient thermal simulation was surface heat convection. A steady state 3D FE flow calculation was performed to determine the average velocity distribution around the test rig at 1500 $1 / \mathrm{min}$. The surface heat convection coefficient model was 


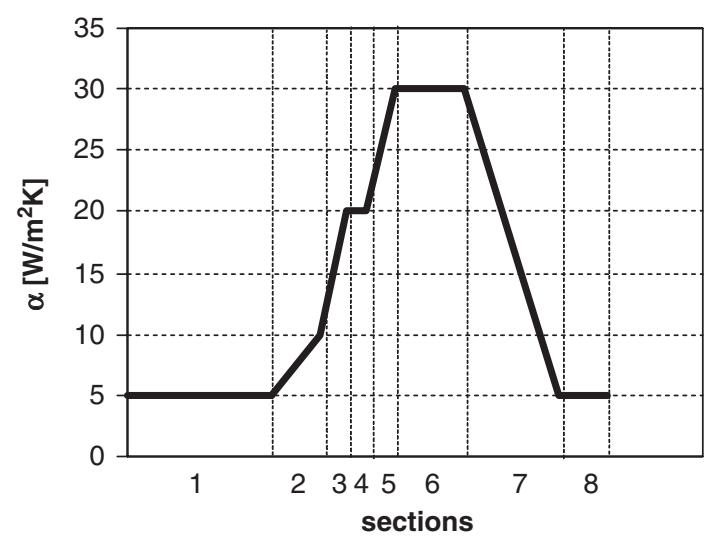

Fig. 9. The surface heat convection coefficient distribution along the geometry of steel disc (see Fig. 7).

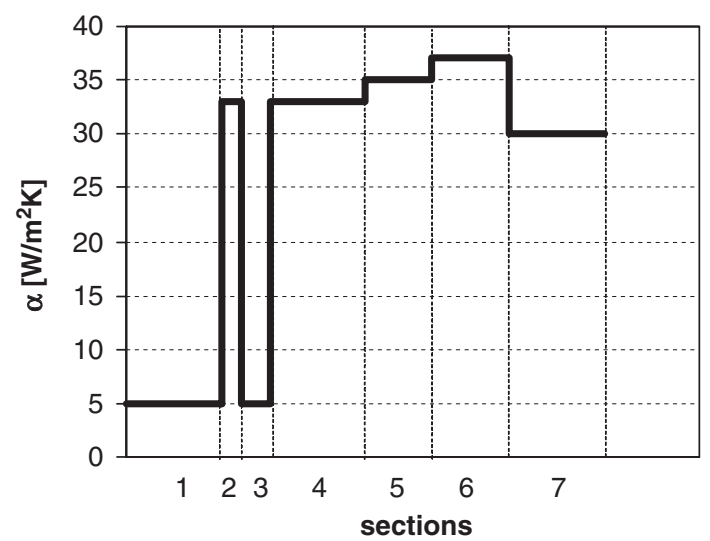

Fig. 10. The surface heat convection coefficient distribution along the geometry of ceramic side (see Fig. 8).

prepared by Nusselt equations based on velocity distribution. The changing surface heat convection coefficient is shown in Figs. 9 and 10; the locations are shown in Figs. 7 and 8 .

\subsection{Temperature measurement by thermocouples of macro temperature state of test rig}

Temperature measurement was performed in three different locations of the steel disc by thermocouples (see Fig. 1); the locations are shown in Fig. 11. The duration of the temperature measurement was always the first 5 seconds of each step of the friction test. These data were constituted a reference for macro transient thermal analysis.

\section{Intermediate scale contact and thermal analysis}

The macro scale analysis could provide the macro temperature state (nominal temperature state in the literature), but the real temperature development in the contact region demanded a detailed analysis, where the real contact area would change in time and in space as the

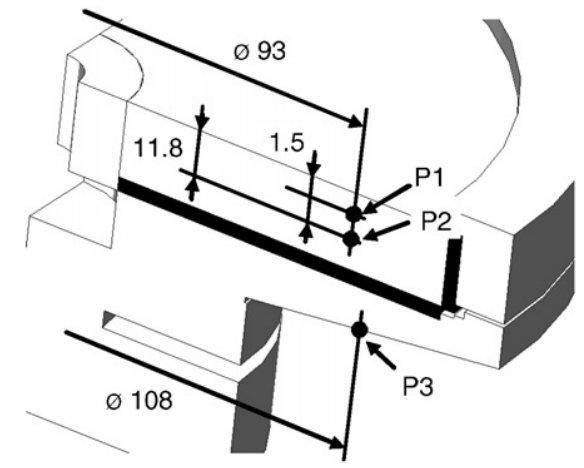

Fig. 11. The thermo couple temperature measurement locations below the contact region.

temperature distribution does. Intermediate analysis focuses on the contact and thermal processes in the contact region considering surface roughness.

The intermediate scale analysis almost had the same structure as above, but in the moving heat source solution the location and magnitude of the real contact area were changing.

\subsection{Real surface topographies and geometrical condition of the contact simulation}

Three dimensional surface roughness measurement was performed by a Perthen stylus instrument. The sampling density of the measurement was $50 \mu \mathrm{m}$ by $50 \mu \mathrm{m}$, which means we had information from the surface in each $50 \mu \mathrm{m}$. The measured area was $5.5 \mathrm{~mm}$ by $6.5 \mathrm{~mm}$, shown in Figs. 12 and 13 in the case of steel and ceramic, respectively. A worn groove was generated on the steel surface; while a table-like worn shape occurred on the surface of the ceramic. The worn groove had a periodic wearing character.

\subsection{Contact sliding simulation}

The continuous sliding motion is approximated by 10 consecutive discrete steps. The real contact area and pressure distribution were determined by contact sliding simulation that consists of the FE contact solutions of 10 consecutive steps. The incremental step of the sliding simulation was $50 \mu \mathrm{m}$, corresponding to the discretization of the measured surface topography. Thus the contact sliding simulation considers $0.5 \mathrm{~mm}$ long sliding. The topographies constituted the geometrical inputs of contact analysis. From the fits of the topographies the initial clearance distribution could be determined for the 10 consecutive steps, which were the input required for the contact FE simulation. The initial gap is the distance between the roughness profiles in the direction of the applied load (normal) at a just touching relative position. This produced a surface in $3 \mathrm{D}$ as shown in Fig. 14. The FE mesh with material discretization and the load and 


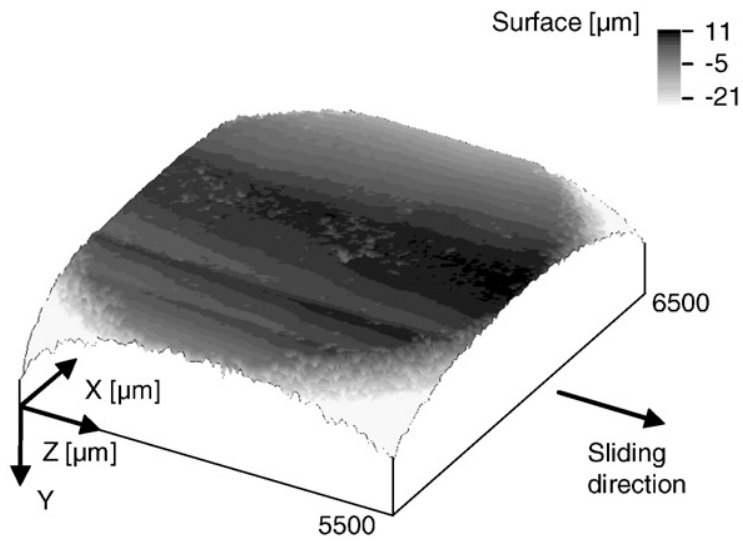

Fig. 12. The surface roughness of the table like worn surface of a ceramic palette after 300 repetitions.

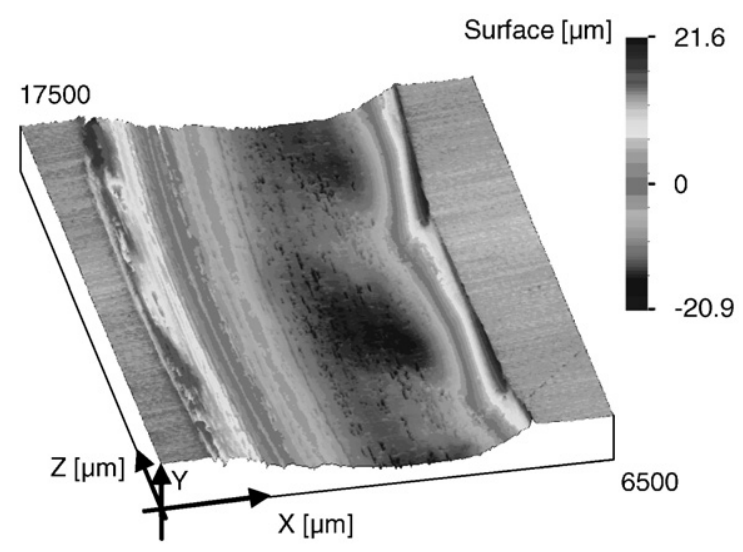

Fig. 13. The surface roughness of the worn groove of the steel disc after 300 repetitions.

boundary conditions are shown in Fig. 15. The load was uniform pressure calculated by $100 \mathrm{~N}$ normal force. The boundary conditions were rigid supports. Material properties at room temperature were used, thus the real contact areas and the contact results were valid at room temperature. The component materials had linear elastic behaviour.

\subsection{Substitution model of the real contact area}

The contact calculation produced many individual contact points in each consecutive step. They did not provide continuous contact areas due to surface data resolution. At the same time the size of the FE model (more than 450000 elements) did not allow a higher resolution to apply. Therefore an individual square cell area was defined in each contact point; in this manner the real contact areas of each step were modelled. The cell size was the smallest unit of surface data resolution: $50 \mu \mathrm{m}$ by $50 \mu \mathrm{m}$ square. Substitutional static FE models were prepared using the real contact area definition above. In this case the load was a uniform pressure $p_{i, j}(t)$ at location $i$ of step $j$,

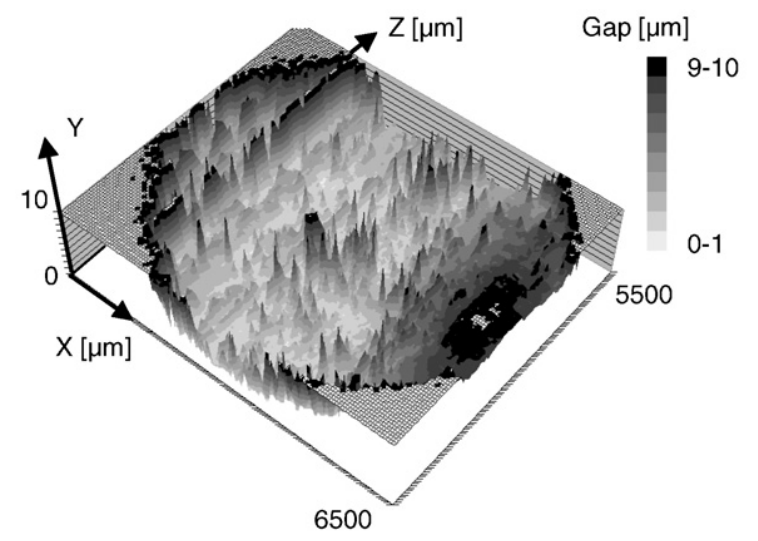

Fig. 14. The initial gap distribution of a step of the contact simulation (the smaller values have bigger possibility to contact).
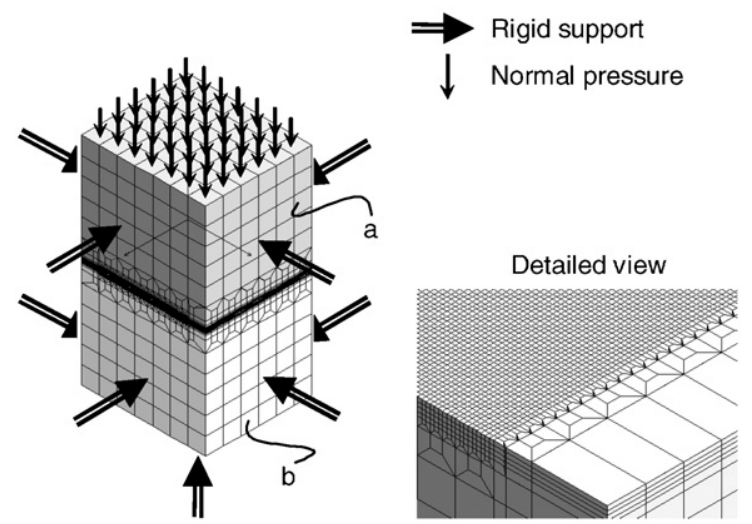

Fig. 15. The intermediate contact FE model, mesh, load, boundary conditions, detailed view of the steel disc mesh and material discretization: (a) ceramic side, (b) steel disc.

where contact arises

$p_{i, j}(t)=F_{c i, j}(t) / A^{*}[\mathrm{~Pa}]$,

where $F_{c i, j}$ is the actual contact force at location $i$ of step $j$, and $A^{*}$ is the constant area of an individual cell. This normal pressure distribution was the input of the thermal sliding simulation, which is discussed in the next paragraph.

\subsection{Thermal sliding simulation}

The contact sliding simulation provided the normal pressure distribution of ten consecutive steps. This block of 10 steps simulated a $0.5 \mathrm{~mm}$ sliding, on the contrary the aim was a $183 \mathrm{~mm}$ long simulation modelling (about the first $\frac{1}{3}$ revolution). The $\frac{1}{3}$ revolution would need 3895 pieces with different contact solutions for the $183 \mathrm{~mm}$ long transient thermal sliding simulations, which is practically impossible due to the enormous CPU time and database required. To reach the goal above, the block of 10 consecutive contact solutions was repeated step by step during the sliding, so a longer simulation could be performed. The heat flux power $\dot{q}_{i, j}(t)$ of each contact point of an individual step $j$ of sliding as calculated from 
the proper normal pressure of the appropriate position $i$ :

$\dot{q}_{i, j}(t)=p_{i, j}(t) \mu(t) v(t) \beta(t)\left[\mathrm{W} / \mathrm{m}^{2}\right]$,

in the case of steel disc and

$\dot{q}_{i, j}(t)=p_{i, j}(t) \mu(t) v(t)(1-\beta(t))\left[\mathrm{W} / \mathrm{m}^{2}\right]$,

in the case of ceramic side.

The correct solution of heat partition of intermediate level would have been the method applied above (see Section 3.4) in each position that had a different heat partition in each step. This process was limited due to the size of the model (the element number would have been approx. 1000000 pieces). The heat partition of intermediate level was solved in an iterative way. In the course of determining the intermediate level heat partition function, the condition was the identical maximum contact temperature of each step.

The applied FE mesh with the load is shown in Fig. 16, zero surface heat convection is assumed in the contact region. The velocity and the coefficient of friction in time are shown in Fig. 17. Reference measurements were performed by thermo-graphic camera (Fig. 1) to verify the calculations.

\subsection{Temperature measurement by thermo-graphic camera}

The rubbing surface temperature of one of the six ceramics was measured by thermo-graphic camera. The camera measured the maximum and the mean contact temperature of the ceramic surface through a hole drilled into the stationary steel disc when the ceramic was in front of the hole. On this way the temperature data of each revolution were gained. Obviously the ceramic did not have a solid connection when temperature was measured, thus the camera could not measure real temperature peaks during sliding. This hypothesis was verified by the results of measurement showing a small difference between the maximum and the average temperatures measured. The resolution of the camera is $56 \mu \mathrm{m}$, that is, in the range of the numerical discretization.

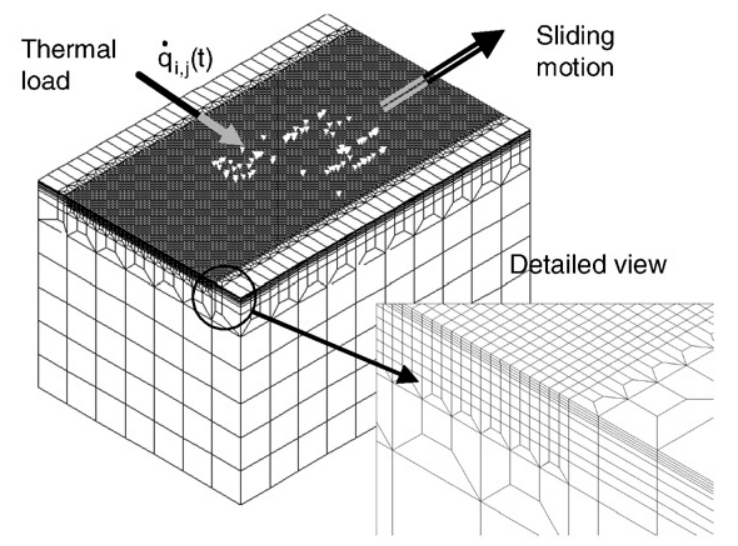

Fig. 16. The intermediate transient thermal model: mesh, load, detailed view of mesh of steel disc.

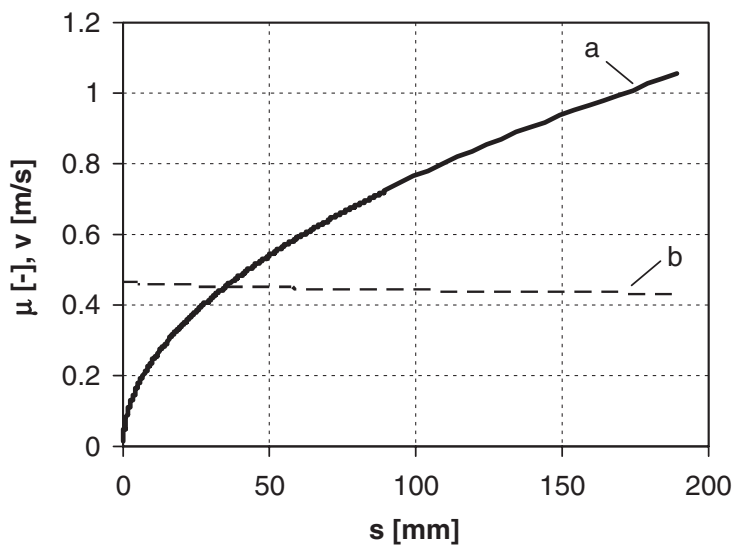

Fig. 17. Input parameters of the intermediate thermal sliding simulation: (a) the sliding velocity, (b) the coefficient of friction in function of the sliding distance.

\section{Results, verifications}

\subsection{Heat partition of different stages}

The results of heat partition at different scale analyses are shown in Fig. 18. Heat partition was changing in time and its character was different due to the different values of the Peclet number and the accelerated sliding motion. The reason for the different Peclet numbers was the different semi-axis of the contact area, in the case of macro stage analysis it was $2 \mathrm{~mm}$ while in the case of a bigger contact spot of intermediate scale it was about $100 \mu \mathrm{m}$. Thus the Peclet number was 20 times higher in the case of macro level than in the case of intermediate level. The initial values were identical in the cases of macro and intermediate scales, but at $183 \mathrm{~mm}$ sliding the macro heat partition of the steel disc reached $95 \%$ and the intermediate one reached $72 \%$.

\subsection{Results and verification of macro scale analysis}

The maximum temperature values in function of the time of the first step of the friction test are shown in Fig. 19. In this diagram the axisymmetric and the $3 \mathrm{D}$ moving heat source model results are presented in terms of the components. The maximum temperature results of the moving heat source modelling of the steel disc and the axisymmetric model of the ceramic side were in good agreement, the error is less than $3 \%$. At the same time the results of axisymmetric model of the steel disc was not identical with the result of the moving heat source with the same heat partition because the distributed model cannot describe the moving local effect particularly in the case of higher Peclet numbers. Kónya et al. [22] conclude that the distributed heat source technique can describe the temperature development of the macro environment except the closer area just below the contact surface. This way the distributed axisymmetric model of the steel disc provides good temperature values in the measured positions 


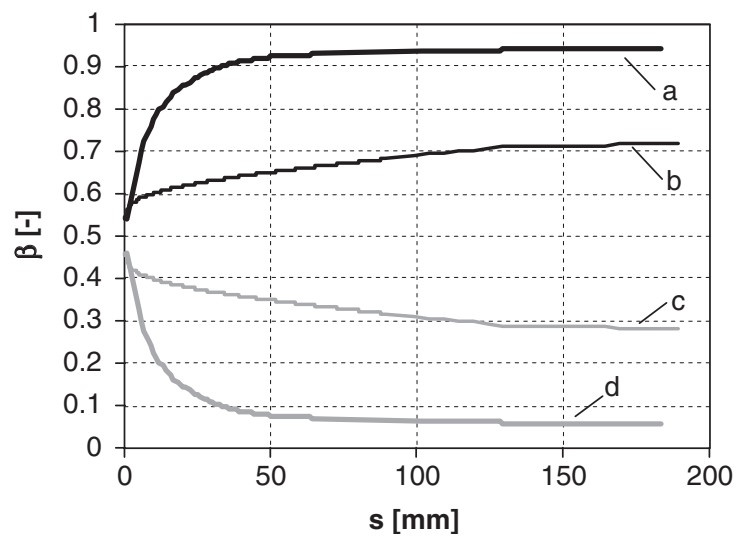

Fig. 18. The heat partitions of steel disc of (a) macro level and (b) intermediate level, (c) the heat partitions of ceramic of intermediate level and (d) macro level in function of the sliding distance.

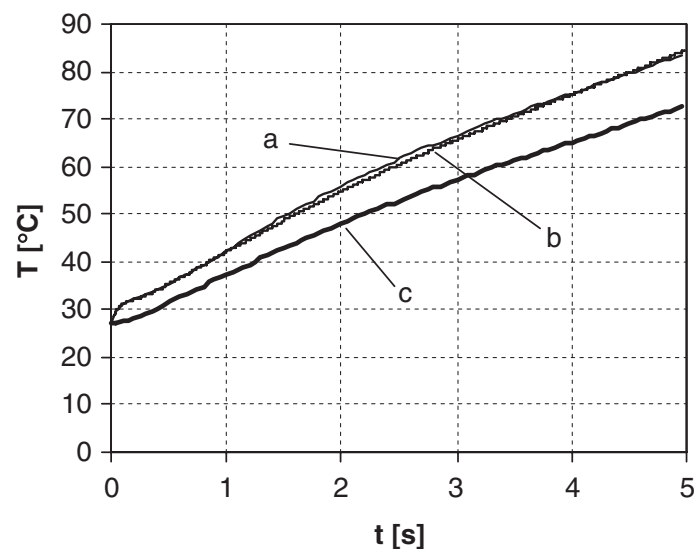

Fig. 19. The macro scale maximum temperature results in time: (a) axisymmetric model of ceramic, (b) moving heat source model of steel disc, (c) axisymmetric model of steel disc with distributed heat source.

compared with the measurements, as is shown in Fig. 20. The moving heat source model is a local model, at the same time the axisymmetric model contains the whole macro environment. Therefore the axisymmetric model with the distributed heat source and the 3D model with the moving heat source together can describe the whole temperature state of the macro environment of the steel disc.

\subsection{Contact results of intermediate stage}

Based on the definition of the real contact area in Section 4.3, one real contact area from the 10 consecutive solutions is shown in Fig. 21. During sliding the initial surfaces disappear and new geometries are generated, consequently the magnitude of the contact area is always different. The $A_{R} / A_{W}$ ratio was defined as the actual real contact area divided by the estimated nominal worn area. The $A_{R} / A_{W}$ ratios of the contact surfaces are shown in Fig. 22. The contact stress distribution of a step of consecutive contact solutions, based on the real contact area definition, is shown in Fig. 23.

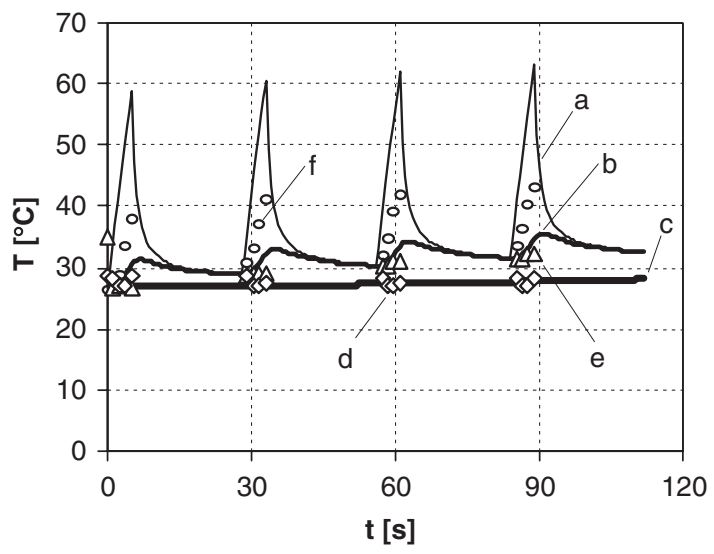

Fig. 20. The temperature of different location in function of the time of steel disc; the calculated results of axisymmetric model: at (a) P1, (b) P2-, (c) P3 position and measured by thermocouples: (f) circles at P1, (e) triangles at P2, (d) squares at P3 (see Fig. 11).

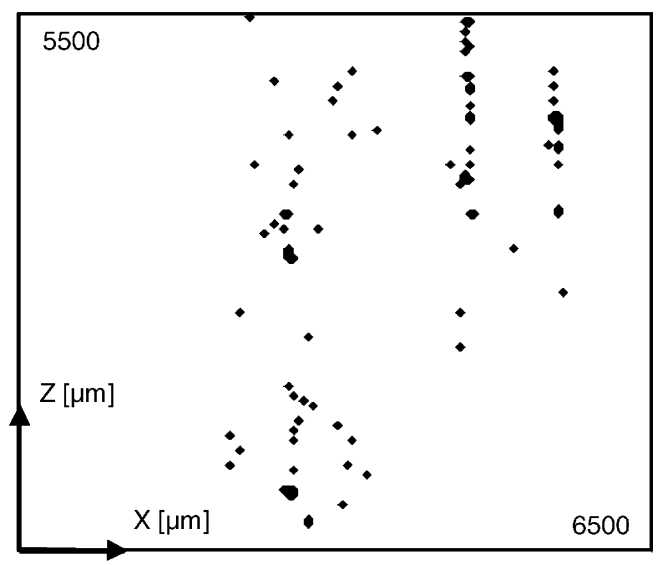

Fig. 21. The real contact area of a contact solution of ten steps simulation.

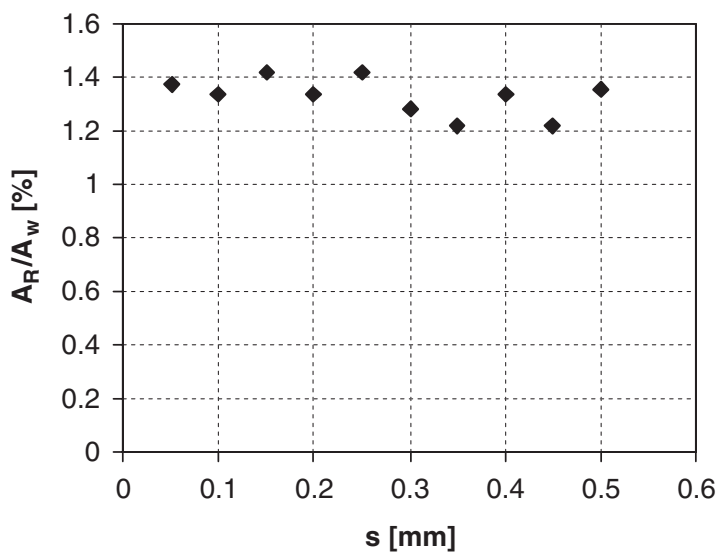

Fig. 22. The $A_{R} / A_{W}$ ratio of real contact area in function of the sliding distance (in the course of ten step sliding simulation). 


\subsection{Thermal results and verification of intermediate stage}

The measured and the calculated maximum temperatures are shown in Fig. 24. The calculated values in the predicted region of the measurement verify the numerical calculations.

\subsubsection{Observations in the moving system}

The calculated maximum contact temperatures of the counterparts are shown at each $4 \mathrm{~mm}$ in Fig. 25. The deviation of the maximum contact temperature of both components was less than $5 \%$. In the moving system during the observation our view moved together with the ceramic palette. During sliding many permanent and many temporary warm spots were evaluated. Two permanent spots, \#1 and \#2 in Fig. 26, were selected to investigate the contact temperature variation in time. The contact temperature variation of the counterparts of permanent warm spots \#1 and \#2 are shown in Fig. 27 in the sliding

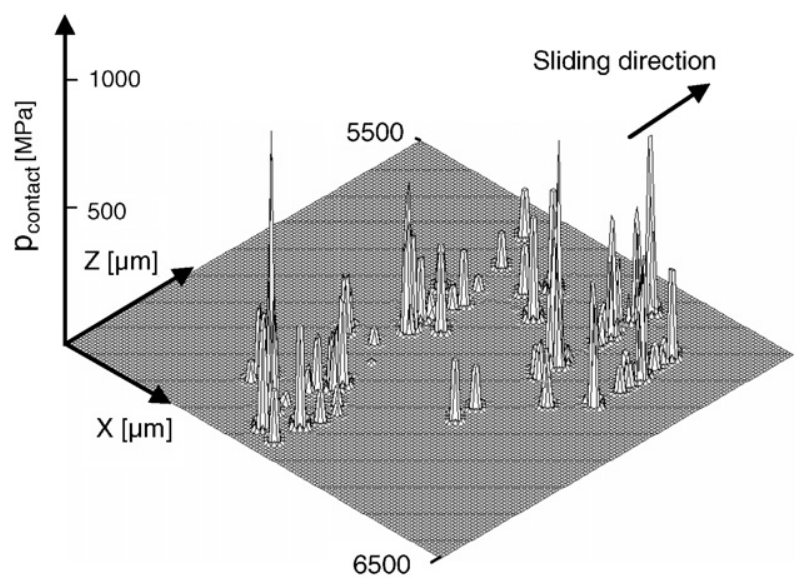

Fig. 23. The normal pressure distribution, which based on real contact area definition, of a contact solution of 10 step simulation.

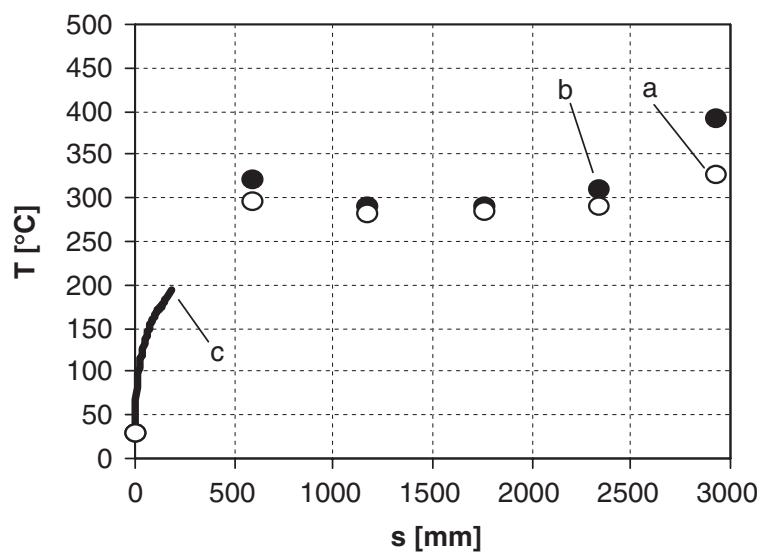

Fig. 24. The temperature results of calculation and measurement: the measured mean (a) and maximum (b) temperatures of the ceramic, calculated maximum temperature of ceramic (c).

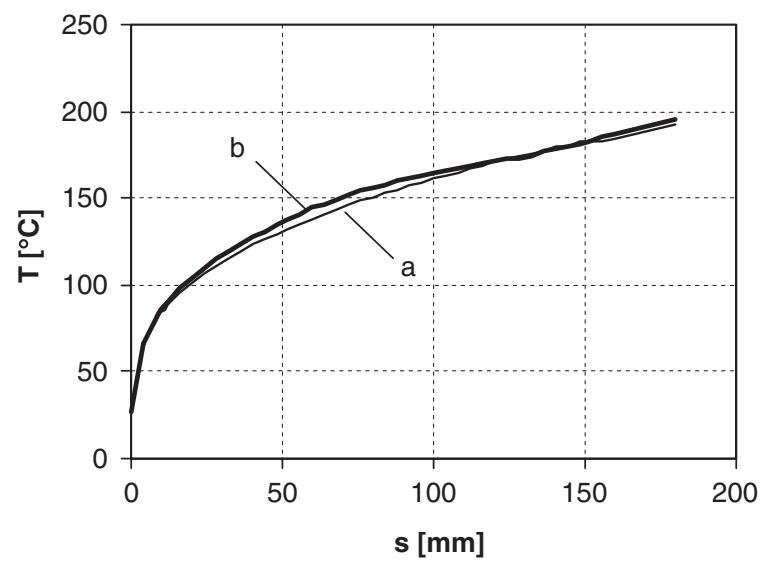

Fig. 25. The maximum temperatures calculated of the steel disc (a) and the ceramic (b) in term of the sliding distance.

interval (from 180 to $183 \mathrm{~mm}$ ). Based on these collected data the following could be observed:

(1) The time dependent intermediate heat partition function (Fig. 18) did not completely provide the accordance of contact temperatures.

(2) The contact temperature of the steel disc was more sensitive to thermal load variation.

Based on the first observation, the time dependent heat partition function (Fig. 18) had to have oscillation to fulfil the condition of identical contact temperatures. Thus the heat partition had to oscillate around a time dependent average function (Fig. 18).

The second observation concludes that the part with a moving heat source (steel disc) is always more sensitive to thermal load variation than the part with a stationary heat source (ceramic). The first reason is that the warm mass is much smaller in the case of a moving heat source. In our case, at the end of our simulation the temperature front of $100{ }^{\circ} \mathrm{C}$ reached the $25 \mu \mathrm{m}$ depth below the contact surface, while in the case of ceramic it was $65 \mu \mathrm{m}$ (Fig. 28). The warm mass accumulates thermal energy that can be transferred back if the thermal load is decreasing. Thus the warm mass is the damper in this dynamic system. The other damper is the specific heat. The warm region is always thinner as sliding velocity is increasing in terms of the part with moving heat source; therefore the high specific heat is the possible way to damping contact temperature fluctuations. The contact temp curves of the ceramic demonstrate, in Fig. 27, the repeating contact pressure character; at the same time, the results of the steel disc show some perturbances due to the fact that the depth of the warm region reaches the limit of the application of FE mesh discretization. For this reason, the FE thermal simulation was stopped at $183 \mathrm{~mm}$ sliding distance.

\subsubsection{Observations in the stationary system}

In the steel disc system during the observation, our view is fixed to the stationary steel disc. Two points were 


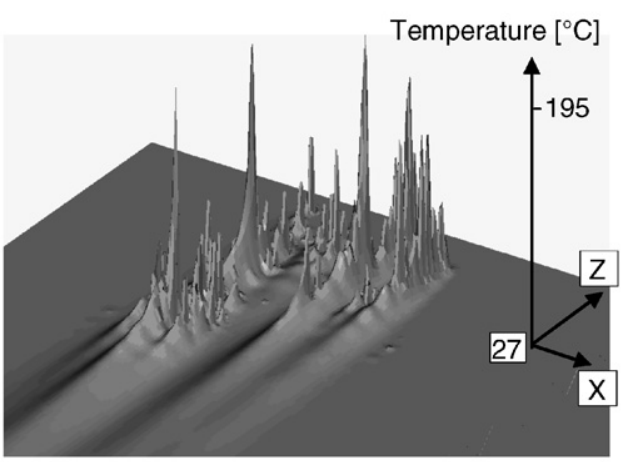

(Ia)

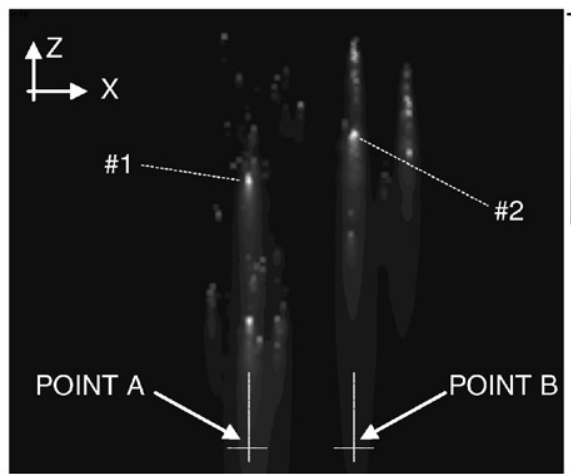

(Ib)

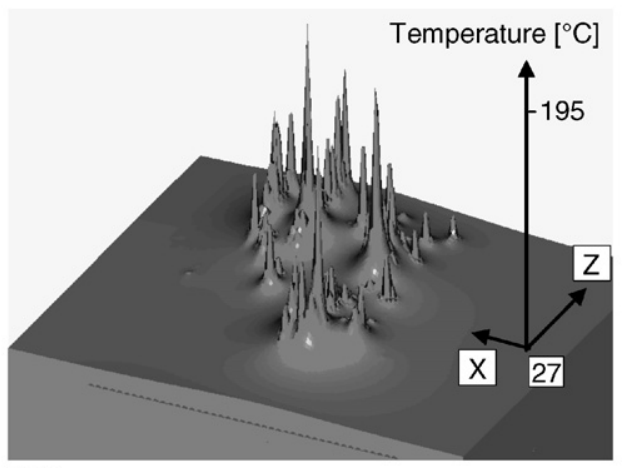

(IIa)

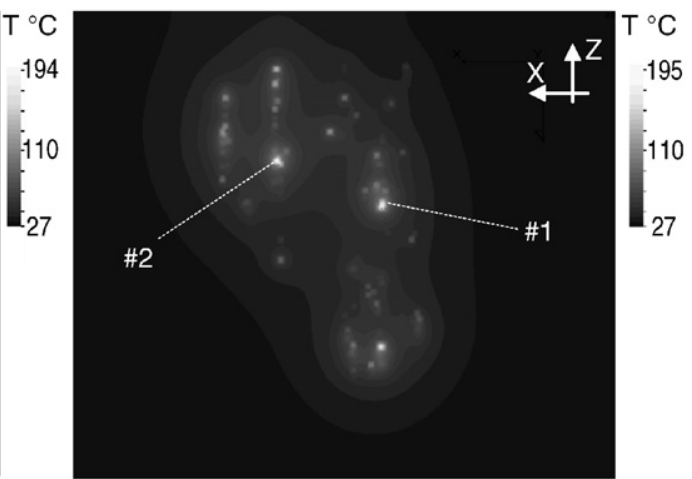

(IIb)

Fig. 26. The contact temperature distribution of steel disc (I/a and $\mathrm{I} / \mathrm{b})$ and the ceramic palette (II/a and II/b) at $183 \mathrm{~mm}$ sliding of the intermediate scale sliding simulation.

selected (points A and B in Fig. 26) on the steel worn groove surface to analyse temperature variation while the ceramic was sliding above them, in the interval of 160 to $169.5 \mathrm{~mm}$ sliding. Fig. 29 shows the temperature of the points in time. While the whole contact region sliding through points, 18 heating up-cooling down sections were generated and some of them had high temperature jumps. The local gradient in time of the temperature of the points could characterize the speed of heating and cooling phenomena as it is shown in Fig. 30. The local gradient in time alternated between the values of -1500 and $2500{ }^{\circ} \mathrm{C} / \mathrm{ms}$ on the surface, which indicates really fast heating and immediately after cooling phenomena, although the sliding velocity was about $1 \mathrm{~m} / \mathrm{s}$. The values above were valid on the contact surface, but the local gradient in time was decreasing in the depth direction. Fig. 31 shows the temperature distribution just below point $\# 1$ after $179.55 \mathrm{~mm}$ sliding. The region of the high temperatures was the upper $20 \mu \mathrm{m}$. In the upper $20 \mu \mathrm{m}$ region just below the contact surface, $95^{\circ} \mathrm{C}$ temperature decrease occurred, which illustrates the geometrical limitation of the temperature fluctuation below the contact surface.

The temperature fluctuation causes fluctuating thermal stresses which leads to surface failure. In the case of ceramics this phenomena can be effective due to the thermal shock which is a very important factor of the failure of ceramics.

\section{Discussion}

Multi-scale FE transient thermal analyses were presented to simulate the thermal processes in the course $f$ dry sliding in an alumina-steel friction system.

The heat partition distribution was analysed in the literature $[14,23]$ in the nominal contact area. Many times the research activities [11-13,23] analysed the sliding friction in case of steady states and constant sliding velocities. At the same time, this study applied constant acceleration and characterized transient processes. In this study we focused on the determination of time dependency of heat partition and we applied uniform distributed heat partition over the contact area. Heat partition has nonuniform distribution as it can be seen in [14,23]; at the same time, this study shows that it is changing from time to time and taking the surface roughness into consideration, it is changing by a time dependent oscillation function. Each contact spot of the real contact area has individual oscillating time dependent heat partition.

In this study, at $179.55 \mathrm{~mm}$ sliding distance, the contact temperature gradients in space on the surface reached the $900-1450{ }^{\circ} \mathrm{C} / \mathrm{mm}$ (at $0.99 \mathrm{~m} / \mathrm{s}$ velocity, $7.5 \mathrm{MPa}$ nominal pressure). Tkachuk et al. [4] had similar observations: $550{ }^{\circ} \mathrm{C} / \mathrm{mm}$ in the case of smaller nominal pressure and much higher velocity. Vernesson et al. [2] observed similar processes: $100-150^{\circ} \mathrm{C} / \mathrm{mm}$ in the case of smaller nominal pressure and higher sliding velocities. Of course the values 

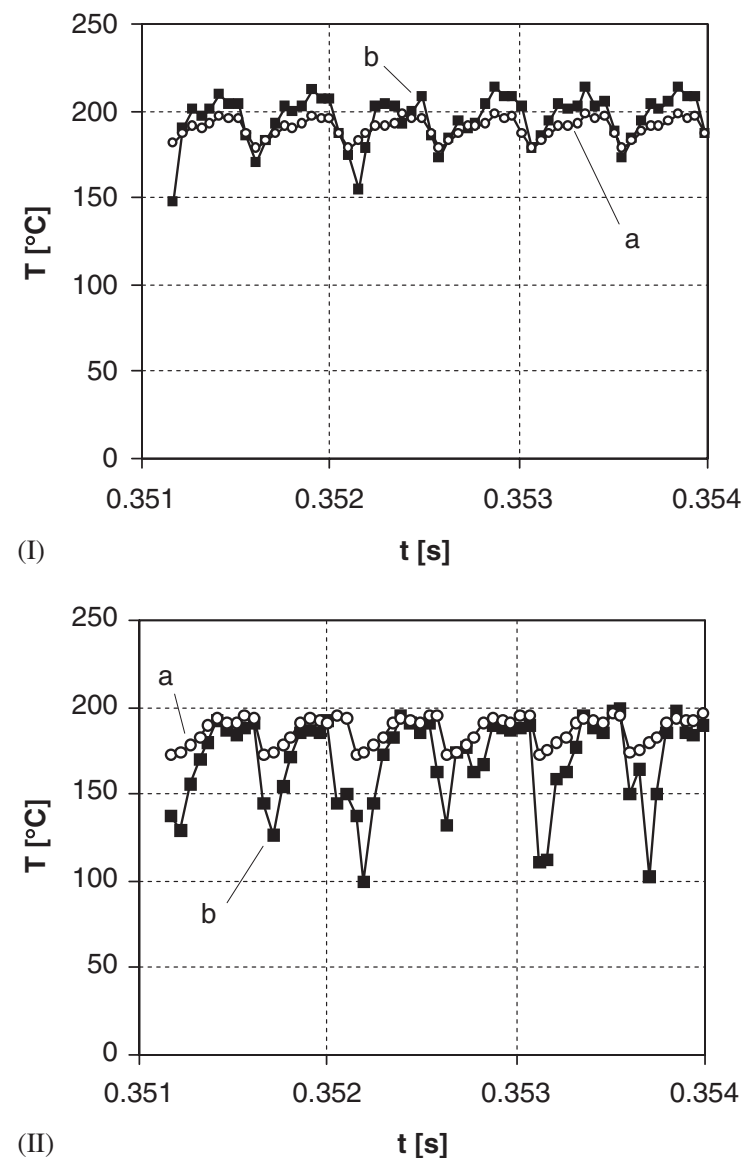

Fig. 27. The contact temperature in time of contact spot \#1 (I) and \#2 (II): on the surface of ceramic (a), of steel disc (b) in the $180-183 \mathrm{~mm}$ sliding distance interval.

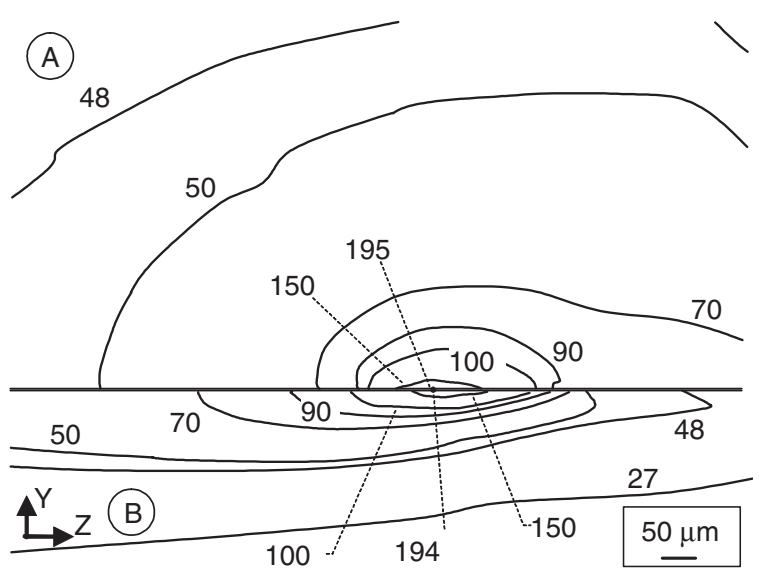

Fig. 28. The temperature distribution in the cross-section of contact spot $\# 1$ at $183 \mathrm{~mm}$ sliding distance: (A) moving ceramic, (B) stationary steel disc.

depend on the resolution of thermo-graphic cameras, sliding pairs and the actual wear mechanisms. Váradi et al. [16] determined much higher values by a localized micro model with fine resolution; the contact temperature gradient on the rubbing surface reached the value of $5000^{\circ} \mathrm{C} / \mathrm{mm}$.

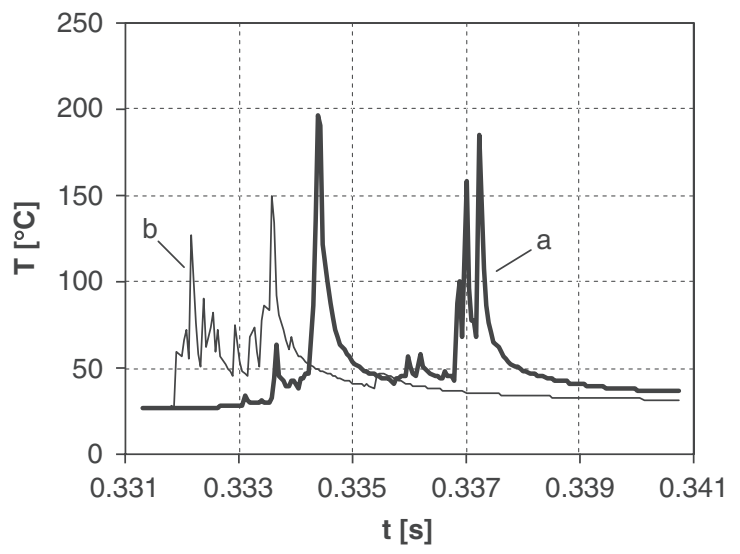

Fig. 29. The local temperature fluctuation in time of point a (a) and point b (b) in the $160-169.5 \mathrm{~mm}$ sliding distance interval.

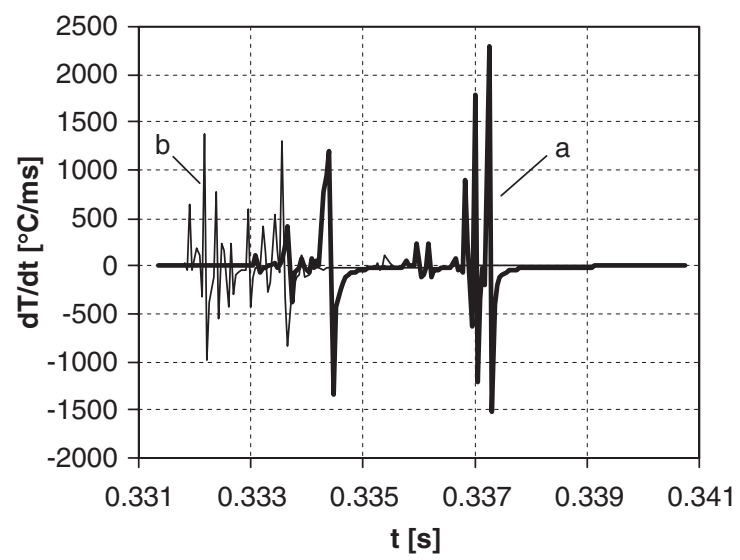

Fig. 30. The local temperature gradient in time on the contact surface of steel disc of point a (a) and point b (b) in the $160-169.5 \mathrm{~mm}$ sliding distance interval.

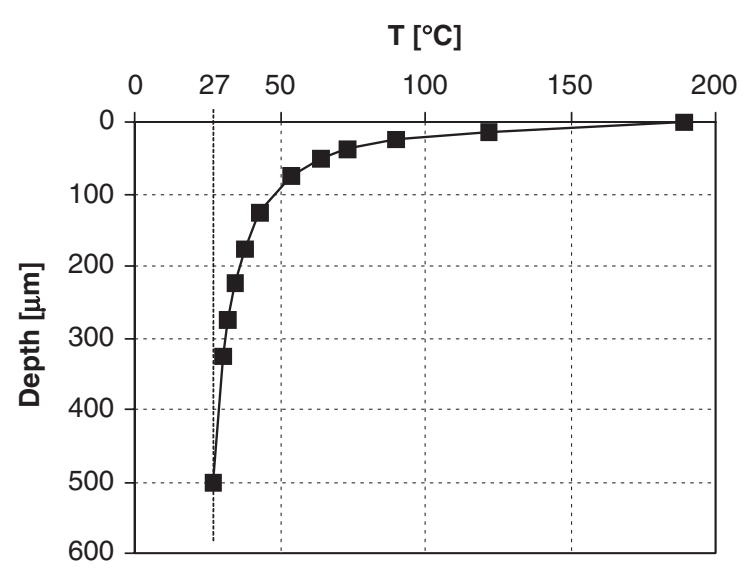

Fig. 31. The temperature distribution of the steel disc just below the contact surface at point $\# 1$ at $179.55 \mathrm{~mm}$ sliding distance.

High temperature fluctuation was analysed on the worn surface of the steel disc; the contact temperature gradient in time changed between -1500 and $2000^{\circ} \mathrm{C} / \mathrm{ms}$. This intensive warming up and immediate cooling down process 
was generated by the small amount of warmed mass of steel disc in the near surface region and by the continuously changing real contact pressure distribution. This contact temperature fluctuation can play a dominant role in the surface failure mechanisms by the thermal stresses generated. Tian et al. [1] observed $50^{\circ} \mathrm{C} / \mathrm{ms}$ local gradient in time in the case of a graphite-alumina coated glass sliding pair at $1.57 \mathrm{~m} / \mathrm{s}$ and similar nominal pressure by TFTC thermocouples.

The calculated temperature is higher and higher as the discretization of the contact surface becomes finer and finer. Representing the effect of the discretization of surface roughness, at the time moment of $0.354 \mathrm{~s}$ $(183 \mathrm{~mm})$ the calculated contact temperature of the macro level reached $33{ }^{\circ} \mathrm{C}$; at the same time, in the case of intermediate-level it was $195^{\circ} \mathrm{C}$. This effect would be much more sufficient if the discretization was $2 \mu \mathrm{m}$ by $2 \mu \mathrm{m}$. Thus the calculated contact temperature depends on the discretization of the rubbing surface.

The consideration of temperature dependent structural and thermal properties and micro-scale modelling indicate the directions of further research activities.

\section{Conclusion}

The macro and the intermediate analyses are necessary for the description of the whole test rig and the whole contact region. The macro one is capable to describe the thermal behaviour of the global system, while the intermediate one can characterize the local behaviour. According to the intermediate analysis, high temperature occurs in the upper $20 \mu \mathrm{m}$ region. In order to yield the real flash temperature, generation would require a micro model with at least 2 by $2 \mu \mathrm{m}$ data resolution of the surface topography.

The heat partition function is different at macro and intermediate levels because of the Peclet number is different due to the different sizes of the contact areas and the accelerating sliding. Heat partition is changing continuously in time due to the accelerated sliding motion. Heat partition is a time dependent oscillation function considering the surface roughness of the sliding pairs.

The real contact area is in the range of $1.2-1.5 \%$ of the estimated nominal worn area. The application of temperature-dependent structural and thermal material properties would be a more accurate solution in each step during sliding friction.

The high maximum temperature gradient in time can provide such high temperatures in a short time that it can be one of the reasons of the decreasing friction coefficient and may affect surface failure mechanisms due to decreasing strength.

The high local temperature gradient in time of a geometrical point can probably cause fast thermally induced pulsating stresses in the near surface region, which might lead to surface fatigue failures.
Based on the verification, the transient thermal sliding simulation can characterize the contact-thermal phenomena and the applied algorithms can be widely applied.

\section{Acknowledgements}

The authors would like to express their thanks to the Hungarian-German Partnership Project (MÖB-DAAD) for the financial support of mobility.

\section{References}

[1] Tian X, Kennedy FE, Deacutis JJ, Henning AK. The development and use of thin film thermocouples for contact temperature measurement. J Tribol Trans ASME 1992;35:491-9.

[2] Vernersson T. Thermally induced roughness of tread-braked railway wheels Part 1: brake rig experiments. Wear 1999;236:96-105.

[3] Arslan A, Albers A. Potenzialabschätzung von Belängen aus monolithischer Keramik in trockenlaufenden Friktionssystemen und die Auswirkungen auf die Systemkonstruktion. 2. Satuskolloquium des SFB 483, 2004, Karlsruhe, Germany.

[4] Tkachuk DV, Bogdanovich PN. Thermal processes at high speed friction. Int J Appl Mech Eng Special issue ITC 2004;9:177-82.

[5] Blok H. Theoretical study of temperature rise at surfaces of actual contact under oiliness conditions, Proceedings of the Institute of Mechanical Engineers general discussion on lubrication, London: Institute of Mechanical Engineers; 1937. p. 222-32.

[6] Jaeger JC. Moving sources of heat and the temperatures of sliding contacts. Proc Roy Soc NSW 1942;76:203-22.

[7] Archard JF. The temperatures of rubbing surfaces. Wear 1958;2: 438-55.

[8] Carslaw HS, Jaeger JC. Conduction heat in solids. 2nd ed. Oxford; 1959.

[9] Allen DN de G. A suggested approach to finite-difference representation of differential equations, with an application to determine temperature-distribution near a sliding contact. J Mech Appl Math 1962;15:11-33.

[10] Kuhlmann-Wilsdorf D. Temperatures at interfacial contact spots: dependence on velocity and on role reversal of two materials in sliding contact. J Tribol Trans ASME 1987;109:321-9.

[11] Tian X, Kennedy FE. Temperature rise at the sliding contact interface for coated semi-infinite body. $\mathbf{J}$ Tribol Trans ASME 1993;115:1-9.

[12] Tian X, Kennedy FE. Contact surface temperature models for finite bodies in dry and boundary lubricated sliding. J Tribol Trans ASME 1993;115:411-8.

[13] Tian X, Kennedy FE. Maximum and average flash temperatures in sliding contacts. J Tribol Trans ASME 1994;116:167-74.

[14] Bos J, Moes H. Frictional Heating of Tribological Contacts. J Tribol Trans ASME 1995;117:171-7.

[15] Abdel-Aal HA, Smith ST. On friction-induced temperatures of rubbing metallic pairs with temperature-dependent thermal properties. Wear 1998;216:41-59.

[16] Váradi K, Bercsey T, Néder Z. Modelling sliding friction between engineering components. Proceedings of the international tribology conference, Nagasaki, Japan, 2000. p. 319-24.

[17] Muzychka YS, Yovanovich MM. Thermal resistance models for noncircular moving heat sources on a half space. J Heat Transfer Trans ASME 2001;123:624-32.

[18] Hou ZB, Komanduri R. On the mechanics of the grinding process, Part II-thermal analysis of fine grinding. Int $\mathrm{J}$ Mach Tools Manuf 2004;44:247-70.

[19] Ling FF, Rice JC. Surface temperatures with temperature-dependent thermal properties. ASLE Trans 1966;9:195-201. 
[20] Hwang DH, Zum Gahr K-H. Transition from static to kinetic friction of unlubricated or oil lubricated steel/steel, steel/ceramic and ceramic/ceramic pairs. Wear 2003;255:365-75.

[21] Bushan B. Modern tribology handbook. Boca Raton, FL: CRC Press; 2001.
[22] Kónya L, Váradi K, Flöck J, Friedrich K. Finite element heat transfer analysis of a peek-steel sliding pair in a pin-on-disk configuration. Tribotest 2001;8:3-26.

[23] Hou ZB, Komanduri R. Analysis of heat partition and temperature distribution in sliding systems. Wear 2001;251:925-38. 